\title{
Glyscavins A, B and C, New Phenolic Glycoside Antioxidants Produced by a Fungus Mycelia sterilia F020054
}

\author{
Byung-Sik Moon, In-Ja Ryoo, Bong-Sik Yun, Kyung-Sook Bae, Kap Duk Lee, \\ Ick-Dong Yoo, Jong-Pyung Kim
}

Received: September 19, 2006 / Accepted: November 6, 2006

(C) Japan Antibiotics Research Association

\begin{abstract}
Three new phenolic glycosides designated glyscavins A (1), B (2), and C (3) were isolated from the culture broth of a fungal strain Mycelia sterilia F020054. Structural elucidation of the compounds was based on the NMR and MS spectroscopic analyses. Glyscavins A, B and $\mathrm{C}$ exhibited higher free radical scavenging activity on superoxide and 2,2'-azinobis(3-ethylbenzothialozinesulfonic acid) cation radical $\left(\mathrm{ABTS}^{++}\right)$than butylated hydroxyanisole (BHA).
\end{abstract}

Keywords glyscavin, phenolic glycosides, Mycelia sterilia, antioxidant

Free radicals abstract hydrogen atoms from biological molecules, which is directly responsible for the detrimental effects of oxidative stress. Free radicals induce oxidative damage of cellular lipids, nucleic acids and proteins, are thought be one of major risks for cancer, atherosclerosis, diabetes mellitus, coronary heart disease, inflammation, cerebral ischemia, skin damages, and various other degenerative diseases [1 4]. Thus, free radical-scavenging antioxidants have the potential as protective agents against various diseases caused by oxidative damage $[5,6]$. We have searched for new biologically active substances from various natural resources [7 10]. As a part of our

J.-P. Kim (Corresponding author), I.-J. Ryoo, B.-S. Yun, K.-S. Bae, I.-D. Yoo: KRIBB, 52 Oeundong, Yuseong, Daejeon 305806, Korea, E-mail: kimjp@kribb.re.kr

B.-S. Moon, K. D. Lee: Department of Chemistry, Dongguk University, Gyeongju, Gyeongbuk 780-714, Korea continuing search for new free radical scavengers as skin protecting agents, we investigated the $n$ - $\mathrm{BuOH}$-soluble portion of the fermentation broth of the fungal strain F020054. Activity guided fractionation of the $n-\mathrm{BuOH}$ extract led to the isolation of three new phenolic glycosides designated glyscavins A (1), B (2), and C (3). This paper describes the isolation and structural elucidation of $\mathbf{1} \sim \mathbf{3}$, primarily by extensive NMR experiments. The antioxidant activities of $\mathbf{1} \sim \mathbf{3}$ evaluated by using the free radicals such as superoxide and $\mathrm{ABTS}^{+}$are also described.

\section{Results and Discussion}

Glyscavins A (1), B (2), and C (3) were obtained as yellow amorphous powders. Acid hydrolysis of $\mathbf{1} \sim \mathbf{3}$ gave Dglucose, which was confirmed by co-TLC with authentic sample and NMR data. The molecular formula of $\mathbf{1}$ was determined as $\mathrm{C}_{18} \mathrm{H}_{24} \mathrm{O}_{8}$ by HRFAB-MS [(M+Na) ${ }^{+}, \mathrm{m} / \mathrm{z}$ 391.1367; calcd: 391.1369] in combination with ${ }^{13} \mathrm{C}$ NMR data. In the IR spectrum, 1 exhibited strong hydroxyl band at $v_{\max } 3402 \mathrm{~cm}^{-1}$, whereas its UV spectrum showed maxima at 223, 271, and $388 \mathrm{~nm}$. The ${ }^{13} \mathrm{C}$ NMR data (Table 1) depicted 18 carbon signals distributed into 1,2,3,4-tetra substituted benzene ring, four olefinic methines, an isolated methylene, one methyl group, and $\beta$-glucopyranosyl group. In the ${ }^{1} \mathrm{H}$ NMR spectrum of $\mathbf{1}$, two aromatic signals were assigned to $\mathrm{H}-5(\delta 7.02, \mathrm{~d}, J=9.0 \mathrm{~Hz})$ and $\mathrm{H}-6(\delta 6.65, \mathrm{~d}$, $J=9.0 \mathrm{~Hz}$ ), which suggested the existence of 1,2,3,4-tetra substituted benzene ring. In addition, four olefinic protons at $\delta 6.71,6.75,6.27$ and 5.81, and $\beta$-linked glucoside at $\delta$ $4.76(1 \mathrm{H}, \mathrm{d}, J=7.2 \mathrm{~Hz}), 3.85(1 \mathrm{H}$, dd, $J=12.0,2.4 \mathrm{~Hz}), 3.65$ $(1 \mathrm{H}, \mathrm{dd}, J=12.0,5.4 \mathrm{~Hz})$, and $3.45 \sim 3.33(4 \mathrm{H}, \mathrm{m})$ were observed. The coupling constant of an anomeric proton at $\delta$ 
$4.76(\mathrm{~d}, J=7.2 \mathrm{~Hz})$ indicated that the glycosyl linkage is $\beta$ configuration. The proton spin system, together with the chemical shift values of the related carbons $[\delta 103.8$ (C1"), $75.1\left(\mathrm{C}-2^{\prime \prime}\right), 78.3$ (C-3"), $71.4\left(\mathrm{C}-4^{\prime \prime}\right), 78.1\left(\mathrm{C}-5^{\prime \prime}\right)$ and $\left.62.6\left(\mathrm{C}-6^{\prime \prime}\right)\right]$ were typical of a glucose moiety.

The protons that were directly attached to carbons were

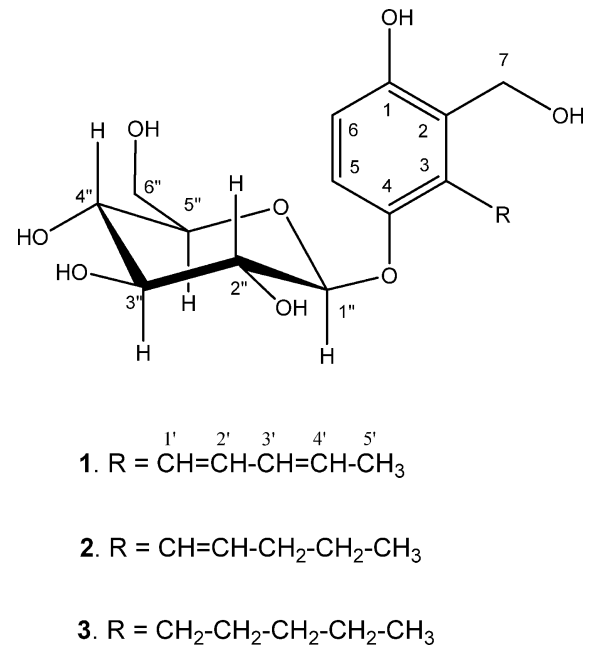

Fig. 1 Structures of glyscavins A (1), B (2), and C (3). assigned with the aid of HMQC spectrum. The HMBC correlations between $\delta 6.71\left(\mathrm{H}-1^{\prime}\right)$ and $\delta 125.8(\mathrm{C}-2)$, 149.9 (C-4) showed the connection of the $\mathrm{C}_{5}$ unit containing olefinic protons with the 1,2,3,4-tetrasubstituted benzene ring. The long-range couplings observed from $\mathrm{H}-7$ to $\delta 131.3(\mathrm{C}-3)$ and $153.3(\mathrm{C}-1)$ in the aglycon place the hydroxy methyl group on $\mathrm{C}-2$. The presence of penta-1,3dienyl moiety was verified by the analysis of ${ }^{1} \mathrm{H}-{ }^{1} \mathrm{H}$ COSY and $\mathrm{HMBC}$ data, and in turn this group was connected to $\mathrm{C}-3$ on the basis of HMBC correlation of $\mathrm{H}-2^{\prime}$ with $\mathrm{C}-3$. The glucopyranosyl group connected to C-4 ( $\delta$ 149.9) through an $O$-glycosydic bond, as was confirmed by the downfield chemical shift of C-4 and the HMBC correlations between the anomeric proton $\left[\delta 4.76\left(\mathrm{H}-1^{\prime \prime}\right)\right]$. The regiochemistry of $\mathrm{C}-1^{\prime}$ and $\mathrm{C}-3^{\prime}$ was determined as trans by proton coupling constant of 15.6 and $15.0 \mathrm{~Hz}$, respectively. The overall structural determination of 1 was based on the detailed analysis of 1D and 2D NMR spectroscopic data including the ${ }^{1} \mathrm{H}$ NMR, ${ }^{13} \mathrm{C}$ NMR, ${ }^{1} \mathrm{H}-{ }^{1} \mathrm{H}$ COSY, HMQC and HMBC spectra. On the basis of aforementioned evidence, the structure of $\mathbf{1}$ was assigned as 4- $O$ - $\beta$-D-glucopyranosyl-2-hydroxymethyl-3-penta-1,3dienyl)phenol.

The molecular formula of glyscavin B (2) was

Table $1{ }^{1} \mathrm{H}(600 \mathrm{MHz})$ and ${ }^{13} \mathrm{C} N M R{ }^{1} \mathrm{H}(150 \mathrm{MHz})$ data for compounds $\mathbf{1}, \mathbf{2}$ and $\mathbf{3}$ in $\mathrm{CD}_{3} \mathrm{OD}(\boldsymbol{\delta}$; $J$ in $\mathrm{Hz})$

\begin{tabular}{|c|c|c|c|c|c|c|}
\hline \multirow{2}{*}{ Position } & \multicolumn{2}{|r|}{1} & \multicolumn{2}{|r|}{2} & \multicolumn{2}{|r|}{3} \\
\hline & ${ }^{13} \mathrm{C}^{\mathrm{a}}$ & ${ }^{1} \mathrm{H}$ & ${ }^{13} \mathrm{C}$ & ${ }^{1} \mathrm{H}$ & ${ }^{13} \mathrm{C}$ & ${ }^{1} \mathrm{H}$ \\
\hline 1 & 153.3 & & 153.1 & & 152.8 & \\
\hline 2 & 125.8 & & 125.8 & & 126.5 & \\
\hline 3 & 131.3 & & 131.4 & & 134.5 & \\
\hline 4 & 149.9 & & 149.5 & & 150.4 & \\
\hline 5 & 118.3 & $7.02, d(9.0)$ & 118.2 & $7.00, d(9.0)$ & 117.9 & $7.00, d(9.0)$ \\
\hline 6 & 114.9 & $6.65, d(9.0)$ & 114.7 & $6.65, d(9.0)$ & 113.9 & $6.60, d(9.0)$ \\
\hline \multirow[t]{2}{*}{7} & 58.2 & $4.72, d(13.5)$ & 58.6 & $4.72, \mathrm{~s}$ & 57.5 & $4.71, d(12.6)$ \\
\hline & & $4.70, d(13.5)$ & & & & 4.69, d (12.6) \\
\hline $1^{\prime}$ & 124.9 & $6.71, d(15.6)$ & 124.6 & 6.59, brt (15.9) & 27.1 & $2.79, \mathrm{~m}$ \\
\hline $2^{\prime}$ & 136.8 & $6.75, \mathrm{dd}(15.6,8.7)$ & 138.2 & $6.04, \mathrm{dt}(15.9,6.9)$ & 31.7 & $1.52, \mathrm{~m}$ \\
\hline $3^{\prime}$ & 134.2 & 6.27, ddd $(15.0,8.7,1.2)$ & 36.8 & $2.23, \operatorname{brq}(6.6)$ & 33.3 & $1.37, \mathrm{~m}$ \\
\hline $4^{\prime}$ & 130.5 & $5.81, \mathrm{dd}(15.0,6.6)$ & 23.6 & $1.53, \mathrm{~m}$ & 23.6 & $1.37, \mathrm{~m}$ \\
\hline $5^{\prime}$ & 18.4 & 1.80, dd $(6.6,1.2)$ & 14.1 & $0.99, \mathrm{t}(6.0)$ & 14.5 & $0.91, \mathrm{t}(6.6)$ \\
\hline $1^{\prime \prime}$ & 103.8 & $4.76, d(7.2)$ & 103.6 & 4.77, d (7.2) & 104.1 & $4.72, d(7.2)$ \\
\hline $2^{\prime \prime}$ & 75.1 & 3.45 , brt (8.4) & 75.0 & 3.45 , brt (8.4) & 75.2 & 3.45 , brt (8.4) \\
\hline $3^{\prime \prime}$ & 78.3 & $3.42, \mathrm{t}(9.0)$ & 78.1 & $3.43, \mathrm{t}(9.0)$ & 78.5 & $3.42, \mathrm{t}(9.0)$ \\
\hline $4^{\prime \prime}$ & 71.4 & $3.37, \mathrm{t}(9.0)$ & 71.3 & $3.38, \mathrm{t}(9.0)$ & 71.5 & $3.37, \mathrm{t}(9.0)$ \\
\hline $5^{\prime \prime}$ & 78.1 & $3.33, \mathrm{~m}$ & 77.8 & $3.30, \mathrm{~m}$ & 78.0 & $3.34, \mathrm{~m}$ \\
\hline \multirow[t]{2}{*}{$6^{\prime \prime}$} & 62.6 & $3.65, \mathrm{dd}(12.0,5.4)$ & 62.5 & $3.69, \mathrm{dd}(12.0,5.4)$ & 62.7 & 3.69, dd $(12.0,5.4)$ \\
\hline & & $3.85, \mathrm{dd}(12.0,2.4)$ & & $3.85, d d(12.0,2.4)$ & & 3.87, dd $(12.0,2.4)$ \\
\hline
\end{tabular}




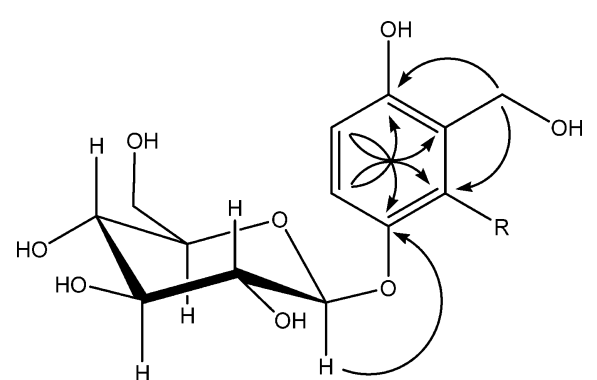

Fig. 2 Significant HMBC correlations for glyscavins.

determined to be $\mathrm{C}_{18} \mathrm{H}_{26} \mathrm{O}_{8}$ on the basis of high resolution FAB-MS [(M+Na ${ }^{+}, m / z$ 393.1522; calcd: 393.1525$]$. The ${ }^{1} \mathrm{H}$ NMR and ${ }^{13} \mathrm{C}$ NMR data as well as $2 \mathrm{D}$ correlation spectra suggested that both of the functional groups and the general substitution patterns present in $\mathbf{2}$ were similar to those of $\mathbf{1}$. The ${ }^{1} \mathrm{H}$ and ${ }^{13} \mathrm{C}$ NMR spectra of $\mathbf{2}$ also resembled those of $\mathbf{1}$ except for the presence of two additional methylenes (C-3' and C-4') instead of two olefinic methines in $\mathbf{1}$. The structure of $\mathbf{2}$ was assigned by the $\mathrm{HMBC}$ experiment in combination with the ${ }^{1} \mathrm{H}-{ }^{1} \mathrm{H}$ COSY and HMQC spectra. The HMBC showed the critical correlations from $\delta 2.23\left(\mathrm{H}-3^{\prime}\right)$ to $\delta 124.6\left(\mathrm{C}-1^{\prime}\right)$ and 14.1 $\left(\mathrm{C}-5^{\prime}\right)$, from $\delta 1.53\left(\mathrm{H}-4^{\prime}\right)$ to $\delta 138.2\left(\mathrm{C}-2^{\prime}\right)$ and 14.1 $\left(\mathrm{C}-5^{\prime}\right)$, establishing the structure of $\mathbf{2}$ as $4-O-\beta$-Dglucopyranosyl-2-hydroxymethyl-3-pent-1-enyl)phenol.

The molecular formula of $\mathbf{3}$ was determined to be $\mathrm{C}_{18} \mathrm{H}_{28} \mathrm{O}_{8}$ on the basis of HRFAB-MS $\left[(\mathrm{M}+\mathrm{Na})^{+}\right.$, $395.1680 \mathrm{~m} / \mathrm{z}$; calcd: 395.1682]. The NMR data of $\mathbf{3}$ showed that the aromatic units and glucose moiety were almost identical to those of $\mathbf{2}$. Significant difference in the ${ }^{1} \mathrm{H}$ NMR spectra between $\mathbf{3}$ and $\mathbf{2}$ were the absence of the signals for the olefinic protons at $\delta 6.59\left(\mathrm{H}^{-1}{ }^{\prime}\right)$ and $\delta 6.04$ $\left(\mathrm{H}-2^{\prime}\right)$ in 2 , and the appearance of the signals for two methylene protons at $\delta 2.79\left(\mathrm{H}-1^{\prime}\right)$ and $1.52\left(\mathrm{H}-2^{\prime}\right)$ in 3. This was confirmed by observing the methylene carbons at $\delta 27.1\left(\mathrm{C}-1^{\prime}\right)$ and $31.7\left(\mathrm{C}-2^{\prime}\right)$ in the ${ }^{13} \mathrm{C}$ NMR spectrum of 3. The HMBC spectrum showed the critical correlations from $\delta 2.79\left(\mathrm{H}-1^{\prime}\right)$ to $\delta 126.5(\mathrm{C}-2), 150.4(\mathrm{C}-4)$ and 33.3 $\left(\mathrm{C}-3^{\prime}\right)$, from $\delta 1.52\left(\mathrm{H}-2^{\prime}\right)$ to $\delta 134.5(\mathrm{C}-3)$ and $23.6(\mathrm{C}-$ $4^{\prime}$ ), establishing the structure of $\mathbf{3}$ as $4-O-\beta$-Dglucopyranosyl-2-hydroxymethyl-3-pentylphenol.

Antioxidant activity of $\mathbf{1} \sim \mathbf{3}$ was evaluated by using superoxide and $\mathrm{ABTS}^{++}$radical scavenging activity of $\mathbf{1} \sim \mathbf{3}$ (Table 2). Compounds $\mathbf{1} \sim \mathbf{3}$ exhibited superoxide radical scavenging activity, in a dose-dependent fashion, with $\mathrm{EC}_{50}$ values of $1.17,1.19$ and $3.63 \mu \mathrm{M}$, respectively. It also scavenged $\mathrm{ABTS}^{++}$with $\mathrm{EC}_{50}$ values of $1.90,2.11$ and $2.42 \mu \mathrm{M}$, respectively. Compounds $\mathbf{1} \sim \mathbf{3}$ showed stronger free radical scavenging activity than BHA used as a
Table 2 Free radical scavenging activity of compounds $1 \sim 3^{\text {a }}$

\begin{tabular}{lcc}
\hline Compound & Superoxide & ABTS $^{+}$ \\
\hline $\mathbf{1}$ & 1.17 & 1.90 \\
$\mathbf{2}$ & 1.19 & 2.11 \\
$\mathbf{3}$ & 3.63 & 2.42 \\
BHA & 6.00 & 11.28 \\
\hline
\end{tabular}

${ }^{\text {a }}$ Results are expressed as $\mathrm{EC}_{50}(\mu \mathrm{M})$ to scavenge $50 \%$ free radical.

standard antioxidant.

\section{Experimental}

\section{General}

Optical rotations were measured at $25^{\circ} \mathrm{C}$ using a JASCO DIP-370 polarimeter. The UV spectra were recorded on a Shimadzu UV-260 spectrophotometer. FT-infrared spectroscopy was done on a FT-IR Equinox 55 spectrometer using $\mathrm{KBr}$ pellets. ${ }^{1} \mathrm{H}$ and ${ }^{13} \mathrm{C}$ NMR spectra and 2D NMR experiments were recorded in $\mathrm{CD}_{3} \mathrm{OD}$ on a Bruker DMX 600. Chemical shifts of ${ }^{1} \mathrm{H}$ and ${ }^{13} \mathrm{C}$ NMR are given in $\delta$ values (ppm) referenced to the methyl group of $\mathrm{CD}_{3} \mathrm{OD}$ at 3.30 and $49.9 \mathrm{ppm}$, respectively, as an internal standard. ESIMS data were obtained using a JEOL JMSSX $102 \mathrm{~A}$ instrument at $70 \mathrm{eV}$. HRFAB-MS spectra were measured on a JEOL JMS HX-110 mass spectrometer with matrix of triethanolamine. Open column chromatography was carried out on silica gel 60 (70 230 mesh, Merck) and Sephadex LH-20 (Pharmacia Co. Ltd.). Analytical TLC was performed with Kiesel gel $60 \mathrm{~F}_{254}$ (Merck) without activation. HPLC was carried out with a Waters HPLC instrument equipped with a Waters 996 photodiode array detector set at $200 \sim 600 \mathrm{~nm}$ and a Waters 515 pump, using a $\mathrm{C}_{18}$ (YMC J'spherel ODS-H80 $150 \times 20 \mathrm{~mm}$ ). Control of the equipment, data acquisition, processing, and management of chromatographic information were performed by Waters Millennium 2000 software program.

\section{Organism and Fermentation}

The producing fungus, strain F020054, was isolated from a soil sample collected at Nodong cave in Chungbuk province, Korea. The taxonomic study of the strain was conducted by the staff of Korea Research Institute of Bioscience and Biotechnology, Korea. The strain showed very low homology with reported fungal organisms, and did not form spores. Thus, the strain was tentatively named as Mycelia sterilia F0200054. The strain was deposited at 
the Korean Collection for Type Culture (KCTC), under accession No. KCTC 1089BP. For maintenance on agar slants and submerged cultures, the fungus was grown on PDA medium (potato dextrose broth $2.0 \%$, agar 1.8\%). For long-term maintenance, the strain was preserved in an YPS medium (glucose $2.0 \%$, yeast extract $0.2 \%$, polypeptone $0.5 \%, \mathrm{MgSO}_{4} 0.05 \%$. $\mathrm{KH}_{2} \mathrm{PO}_{4} 0.1 \%, \mathrm{pH} 6.0$ ) containing $15 \%$ glycerol at $-70^{\circ} \mathrm{C}$.

A loopful of the strain was inoculated from a PDA (Difco Co.) slant culture into 500-ml baffled Erlenmeyer flasks containing $120 \mathrm{ml}$ of YPS medium. The flasks were shaken at $28^{\circ} \mathrm{C}$ on a rotary shaker at $140 \mathrm{rpm}$ for 3 days. Ten $\mathrm{ml}$ of the seed culture was inoculated into $500-\mathrm{ml}$ baffled Erlenmeyer flasks each containing $120 \mathrm{ml}$ of the same culture medium. The fermentation was carried out at $28^{\circ} \mathrm{C}$ for 7 days on a rotary shaker at $140 \mathrm{rpm}$.

\section{Extraction and Isolation}

A total of 12 liters of the cultures was filtered to separate the broth filtrate and the mycelium cake. The broth filtrate was sequentially extracted with $\mathrm{CHCl}_{3}$ and $n$ - $\mathrm{BuOH}$. The $n-\mathrm{BuOH}$ extract was concentrated in vacuo and then was subjected to a silica gel column (Merck silica gel 60 ), eluted with $\mathrm{CHCl}_{3}-\mathrm{MeOH}$ mixtures of increasing polarities $(50: 1$ to $3: 1)$, to obtain three active fractions. The active fractions were concentrated and rechromatographed on a silica gel column eluted with $\mathrm{CHCl}_{3}-\mathrm{MeOH}(20: 1)$ to afford active fractions. The active fractions were evaporated and subjected to Sephadex LH20 column chromatography eluted with $\mathrm{MeOH}$. An active fraction was purified by reversed-phase preparative HPLC (YMC J'sphere ODS-H80, 150 $\times 20 \mathrm{~mm}$ ) developed with $40 \%$ aqueous $\mathrm{MeOH}$ at a flow rate of $6.0 \mathrm{ml} /$ minute. The peaks with a retention time of 36,46 and 56 minutes were collected and concentrated to give dark yellow powdery materials of $\mathbf{1}$ (8.7 mg), 2 (15.2 mg), and $\mathbf{3}$ (159.6 mg).

\section{Superoxide Anion Radical Scavenging Activity}

Superoxide radical scavenging activity was measured by employing a modified method of Beauchamp and Fridovich [11] as described by Kim [12]. The mixture consisted of $140 \mu \mathrm{l}$ of $0.030 \mathrm{mM}$ riboflavin, $1.0 \mathrm{mM}$ EDTA, $0.60 \mathrm{mM}$ methionine and $0.030 \mathrm{mM}$ NBT solution in $50 \mathrm{mM}$ potassium phosphate buffer ( $\mathrm{pH} 7.8$ ) and $10 \mu \mathrm{l}$ of a sample solution, which includes the test compounds and the reference compound at various concentrations in DMSO, as well as DMSO as a control. The photoinduced reactions to generate superoxide anion were carried out in an aluminum foil-lined box with two $20 \mathrm{~W}$ fluorescent lamps. The distance between reactant and lamp was adjusted until the intensity of illumination reached 1000 lux. The reactant was illuminated at $25^{\circ} \mathrm{C}$ for 8 minutes. The photochemically reduced riboflavin generated superoxide anion, which reduced NBT to form the blue formazan. The un-illuminated reaction mixture was used as a blank. Reduction of NBT was measured by the absorbance change at $560 \mathrm{~nm}$ before and after irradiation using a microplate. Scavenging activity was calculated from the absorbance changes of control and test samples:

Scavenging activity $(\%)=\left(1-\Delta A_{\text {sample }} / \Delta A_{\text {control }}\right) \times 100$

where $\Delta A_{\text {sample }}$ is the change of the absorbance in the wells containing the tested compounds, and $\Delta A_{\text {control }}$ is the change of the absorbance in the wells containing DMSO instead of the tested compounds.

The $\mathrm{EC}_{50}$ value is defined as the concentration of substrate that causes $50 \%$ loss of the reduced NBT. The assays were performed in triplicate and the absorbance changes were averaged before calculation.

\section{ABTS Cation Radical Scavenging Activity}

The total antioxidant activity of the compounds was determined using the $\mathrm{ABTS}^{++}$scavenging assay of Re [13]. The ABTS cation radical was produced by the reaction between $7.0 \mathrm{mM}$ ABTS and $2.45 \mathrm{mM}$ potassium persulfate in water for 12 hours in the dark at room temperature. The ABTS $^{+}$solution was diluted with PBS until $\mathrm{A}_{734}=0.7$. The reaction was initiated by adding $190 \mu \mathrm{l}$ of $\mathrm{ABTS}^{++}$to $10 \mu \mathrm{l}$ sample solution at $25^{\circ} \mathrm{C}$. The percentage of reduction of $\mathrm{A}_{734}$ was recorded and was plotted as a function of the sample's concentration.

Compound 1: yellow powder; HRFAB-MS $[\mathrm{M}+\mathrm{Na}]^{+}$ $m / z 391.1369$ (calcd for $\mathrm{C}_{18} \mathrm{H}_{24} \mathrm{NaO}_{8}, 391.1369$ ); $[\alpha]_{\mathrm{D}}^{25}$ $-21.9^{\circ}$ (c 0.2, MeOH); IR $v_{\max } 3402,2925,2650,1377$, $1244,1075 \mathrm{~cm}^{-1}$. UV (MeOH) $\lambda_{\max } \mathrm{nm}(\log \varepsilon) 223$ (4.13), 271 (4.12), 388 (3.74); ${ }^{1} \mathrm{H}$ and ${ }^{13} \mathrm{C}$ NMR, see Table 1.

Compound 2: yellow powder; HRFAB-MS $[\mathrm{M}+\mathrm{Na}]^{+}$ $m / z 393.1522$ (calcd for $\mathrm{C}_{18} \mathrm{H}_{26} \mathrm{NaO}_{8}, 393.1525$ ); $[\alpha]_{\mathrm{D}}^{25}$ $-110.7^{\circ}$ (c 0.5, MeOH); IR $v_{\max } 3394,2928,1707,1394$, $1244,1076 \mathrm{~cm}^{-1}$. UV (MeOH) $\lambda_{\max } \mathrm{nm}(\log \varepsilon) 225$ (3.75), 299 (3.12); ${ }^{1} \mathrm{H}$ and ${ }^{13} \mathrm{C}$ NMR, see Table 1.

Compound 3: yellow powder; HRFAB-MS $[\mathrm{M}+\mathrm{Na}]^{+}$ $m / z 395.1680$ (calcd for $\mathrm{C}_{18} \mathrm{H}_{28} \mathrm{NaO}_{8}, 395.1682$ ); $[\alpha]_{\mathrm{D}}^{25}$ $-12.8^{\circ}$ (c 0.2, MeOH); IR $v_{\max } 3368,2928,1657,1359$, $1243,1077 \mathrm{~cm}^{-1}$. UV nm $(\mathrm{MeOH}) \lambda_{\max } \mathrm{nm}(\log \varepsilon): 223$ (3.53), 367 (3.35); ${ }^{1} \mathrm{H}$ and ${ }^{13} \mathrm{C}$ NMR, see Table 1.

Acknowledgment This study was supported by a grant of the Korea Health 21 R\&D Project, Ministry of Health \& Welfare, Republic of Korea. (A050432). 


\section{References}

1. Halliwell B, Gutteridge JMC. Free radicals in Biology and Medicine (3rd ed), pp. 617-783, Oxford University Press, New York (1999)

2. Coyle JT, Puttfarcken P. Oxidative stress, glutamate, and neurodegenerative disorders. Science 262: 689-695 (1993)

3. Fraga G, Shigenaga MK, Park JW, Degan P, Ames BN. Oxidative damage to DNA during aging: 8-hydroxy-2'deoxyguanosine in rat organ DNA and urine. Proc Natl Acad Sci USA 87: 4533-4537 (1990)

4. Diaz MN, Frei B, Vita JA., Keaney JF. Antioxidants and atherosclerotic heart disease. N Engl J Med 337: 408-416 (1997)

5. Gaziano JM, Manson JE, Hennekens CH. Natural antioxidants and cardiovascular disease: observational epidemiologic studies and randomized trials. In Natural Antioxidants in Human Health and Disease. Ed., B. Frei, pp. 387-409, Academic Press, San Diego, California (1994)

6. Keaney JF Jr, Frei B. Antioxidant protection of low-density lipoprotein and its role in the prevention of atherosclerotic vascular disease. Ed., B. Frei, pp. 303-352, Academic Press, San Diego, California (1994).

7. Yoo NH, Kim JP, Yun BS, Ryoo IJ, Lee IK, Yoon ES, Koshino H, Yoo ID. Hirsutenols D, E and F, new sesquiterpenes from the culture broth of Stereum hirsutum. J
Antibiot 59: 110-113 (2006)

8. Choo SJ, Park HR, Ryoo IJ, Kim JP, Yun BS, Kim CJ, Shinya K, Yoo ID. Deoxyverrucosidin, a novel GRP78/BiP down-regulator, produced by Penicillium sp. J Antibiot 58: 210-213 (2005)

9. Yoo NH, Yoo ID, Kim JW, Yun BS, Ryoo IJ, Yoon ES, Nguyen TC, Kim JP. Sterin C, a new antioxidant from the mycelial culture of the mushroom Streum hirsutum. Agri Chem Biotechnol 48: 38-41 (2005)

10. Kim JP, Kim BK, Yun BS, Ryoo IJ, Lee IK, Kim WG, Pyun YR, Yoo ID. Melanocins A, B and C, new melanin synthesis inhibitors produced by Eupenicillium shearii. II. Physicochemical properties and structure elucidation. J Antibiot 56: 1000-1003 (2003)

11. Beauchamp C, Fridovich I. Superoxide dismutase: Improved assays and an assay applicable to acrylamide gels. Anal Biochem 44: 276-287 (1971)

12. Kim JP, Kim BK, Yun BS, Ryoo IJ, LEE CH, Lee IK, Kim WG, LEE SK, Pyun YR, Yoo ID. Melanocins A, B and C, new melanin synthesis inhibitors produced by Eupenicillium shearii. I. Taxonomy, fermentation, isolation and biological properties. J Antibiot 56: 1000-1003 (2003)

13. Re R, Pellegrini N, Proteggente A, Pannala A, Yang M, Rice-Evans C. Antioxidant activity applying an improved ABTS radical cation decolorization assay. Free Radical Biol Med 26: 1231-1237 (1999) 